\title{
Reseña de proyecto de extensión «Encuentro 56 años viviendo con Cristina Peri Rossi»
}

\author{
Claudia Pérez'
}

DOI: https://doi.org/10.37125/ISR.7.1.12

\section{Resumen}

Esta reseña da cuenta del conjunto de actividades estructuradas alrededor del proyecto «Encuentro 56 años viviendo con Cristina Peri Rossi». El objetivo fue homenajear, difundir y dialogar sobre esta autora radicada hace décadas en España, que publicó Viviendo hace 56 años en Montevideo. Para acentuar esa posición dialógica convocamos en coorganización a la Asociación de Profesores de Literatura del Uruguay junto al equipo Teoría Literaria de la Diversidad del Departamento de Teoría y Metodología Literarias de la Facultad de Humanidades y Ciencias de la Educación. Acercarla más a nuestro público, promover la investigación sobre la vasta producción poética, ensayística, narrativa y periodística fueron objetivos que se materializaron en tres actividades: un encuentro en la Biblioteca Nacional, con variada pertenencia de ponentes y mucho público, incluyendo mesa de poetas y lecturas performáticas además de la actividad de producción académica; una actividad de taller para adolescentes con lectura, análisis y producción poética, y la publicación de un libro que incluye todas las ponencias del encuentro, editado por la Comisión Sectorial de Extensión y Actividades en el Medio de la Universidad de la República y la Asociación de Profesores de Literatura del Uruguay, que se difundió gratuitamente. Todas estas actividades generaron conocimiento, sensibilizaron público transgeneracional, reordenaron saberes, estimularon nuevas actividades. También evidenciaron cuán difícil es llevar a cabo acciones organizadas complejas, como componente educativo del proyecto.

Palabras clave: extensión, literatura uruguaya, Cristina Peri Rossi

\section{Introducción}

El proyecto de actividad de extensión «Encuentro 56 años viviendo con Cristina Peri Rossi», presentado a la Comisión Sectorial de Extensión y Actividades en el Medio (CSEAM) de la Universidad de la República, contó con tres instancias diferenciadas y se realizó en el año 2019.

1 Departamento de Teoría y Metodología Literarias, Facultad de Humanidades y Ciencias de la Educación, Universidad de la República. oliviapz@gmail.com 
Esta actividad se coordinó con la Asociación de Profesores de Literatura del Uruguay (APLU), y el Equipo Teoría Literaria de la Diversidad del Depto. de Teoría y Metodología Literarias de la Facultad de Humanidades y Ciencias de la Educación (FHCE). Entendimos que esta cooperación ponía en juego diversos actores: docentes, estudiantes y egresados de nuestra Facultad y profesores de Literatura de enseñanza media, provocando un diálogo y un alcance mayor, propicio a la extensión. Habitualmente, los docentes de enseñanza media organizan sus propios congresos y la Facultad los suyos: ponerlos en diálogo aportó al acercamiento entre estas instituciones y sus diferentes metodologías de aprendizaje. Poner en vínculo las diferentes miradas y la acción en diferentes instancias constituyó un desafío quizás demasiado abarcador. Es necesario tener en cuenta el factor desgaste de los equipos de trabajo. A la hora de programar las actividades, es preciso administrar bien los recursos humanos y no proponerse tantas actividades que excedan los tiempos de cada integrante.

\section{Primera actividad: encuentro}

La primera actividad consistió en la organización del «Encuentro 56 años viviendo con Cristina Peri Rossi», en la Biblioteca Nacional el 20 de agosto de 2019. Participaron más de 25 profesores, estudiantes, egresados, profesores universitarios, profesores del CES Y CFE en calidad de expositores, con una concurrencia completa de más de 150 personas.

Estas fueron las palabras inaugurales a cargo de la autora de esta reseña:

El primer paso es agradecer a todos y todas por estar acá en este Encuentro alrededor de Cristina Peri Rossi y de Lil Castagnet, su compañera del corazón. No solemos considerar públicamente que detrás de una gran figura hay otra gran figura que acompaña, sostiene, da ideas, promueve.

Muchas veces tememos decir: la escritora lesbiana. Nos parece que va en desmedro de su libertad poética, o no compete a su calidad artística. Yo digo poeta lesbiana, en un marco postestructuralista, porque, a pesar de haber mantenido siempre la tensión entre la categoría y la multiplicidad, la considero una escritora lesbiana, que habla desde la voz fáctica de su experiencia, y su objeto de deseo son las mujeres, ya descriptas mediante un narrador masculino o más explícitamente desde una voz que se remite lesbiana.

No me cuesta tampoco decir que ha sido la poeta de mi autodescubrimiento, aquella que leí desde mis 17 años, fascinada por la identificación con Evohé. Pasaron los años y mis lecturas se hicieron más técnicas, pero nunca abandonaron, siguiendo a Jauss, la superación de la dicotomía entre el placer y el juicio crítico, desde mi rol de académica lesbiana.

En el libro Julio Cortázar y Cris (Estuario, 2014) se narra un acontecimiento autobiográfico: «Era la primera vez que leíamos en público, pero no se puede decir que fuera un ato solenne, eso que ambos rechazábamos visceralmente. Se respiraba una atmósfera de complicidad, de camaradería, de quehacer común, que es gozo común.» (p. 60). A eso mismo apuntamos con nuestro Encuentro. 
Y por último, como vamos a escuchar ahora un poema de Cristina especialmente escrito para nuestro Encuentro, quiero referirme a un concepto de Roland Barthes: «le grain de la voix» $(2010,313)$ : «espace (genre) très précis où une langue rencontre une voix [...] ce sera le grain, le grain de la voix» (2010. 319).

Al final de este artículo, adjuntamos el programa a los efectos de evidenciar la dimensión organizativa y expositiva del Encuentro:

\section{Segunda actividad: taller de extensión}

El taller de extensión fue llevado a cabo por Vanesa Artasánchez, Emanuel Andriulis y Romina Serrano. El proyecto de extensión «Encuentro 56 años viviendo con Cristina Peri Rossi» contó con una segunda actividad que consistió en un taller con adolescentes buscando que nos proveyera de insumos para el trabajo sobre la recepción literaria en una población no contaminada con los supuestos literarios, sino en etapa de formación lectora curricular. Hacemos hincapié en la distinción formación curricular puesto que los adolescentes, como el resto de la población, ya están inmersos en un medio que les propone y a veces impone el contacto con mensajes, productos y objetos que cuentan con una elaboración estética: canciones, películas, publicidad, revistas, videojuegos, etcétera.

El taller se llevó adelante el 25 de octubre en el Liceo Espigas. Este liceo está ubicado en la periferia montevideana, en Av. de las Instrucciones un poco antes de Cno. de la Calera, y trabaja con lo que comúnmente se denomina población de contexto crítico. El equipo de talleristas estuvo conformado por Emanuel Andriulis, Vanesa Artasánchez y Romina Serrano; cabe señalar que si bien los tres poseen experiencia docente con adolescentes la conducción del taller se vio facilitada por la participación de la Lic. Romina Serrano quien se desempeñaba como profesora de los grupos seleccionados.

Se trabajó con tres grupos de tercer año de ciclo básico y los objetivos del taller fueron acercar la producción literaria de la autora a adolescentes y generar insumos para la reflexión sobre la recepción de esta literatura en esta población. Se eligió el curso de literatura de tercer año por tratarse del primer año que, en forma curricular, los estudiantes toman contacto con la asignatura. Asimismo, consideramos relevante el acercamiento de una autora nacional viva y de reconocimiento internacional a los estudiantes de tercer año cuyo programa se concentra principalmente en la literatura nacional.

El taller se desarrolló de la siguiente manera: en primera instancia se realizó una presentación biográfica a partir de imágenes, frases y poemas que ilustraran el contexto político y cultural del comienzo de su producción, por ejemplo, a través del poema «Montevideo 70»; al mismo tiempo se indagó en los conocimientos previos y en las interpretaciones que despertaron en los estudiantes estos disparadores. Luego se propuso una actividad de lectura y comentario de distintos fragmentos correspondientes a diferentes libros por parte de los estudiantes. Esta segunda actividad permitió 
visualizar algunos rasgos de estilo, por ejemplo, el uso de la metáfora y la imagen e identificar algunos de los temas que aborda la autora, como lo son el amor y el desamor, la represión militar, la representación y diferencias de género. Este momento de contacto con la producción de Peri Rossi se cerró con la audición del poema inédito «Una tarde de verano» recitado por la propia autora y al que esta considera «... significativo en cuanto a lo que fue la adolescencia y el amor lesbiano».

En los tres grupos, si bien no de forma unánime, se vio una rápida actualización de los temas a situaciones vitales inmediatas: los mandatos de comportamiento según el género, la edad, el origen; la intensidad del sentimiento amoroso o su frustración; la actualidad política ya que en pocos días sucedería el plebiscito por la reforma constitucional conocida como Vivir sin miedo, todos temas que una vez visualizados los interpelaron e intensificaron el interés por la escritura de Peri Rossi.

En forma posterior a la actividad de lectura se propuso una actividad de escritura a partir de lo trabajado, en esta instancia se apreció una apropiación por parte de los estudiantes o bien de los temas o en algunos casos del estilo. Esta última actividad se desarrolló al aire libre, lo que permitió ofrecer una instancia de recreación y libertad de encontrar un espacio de mayor privacidad para la escritura en contacto con el ambiente natural.

A continuación, transcribimos algunas de las producciones:

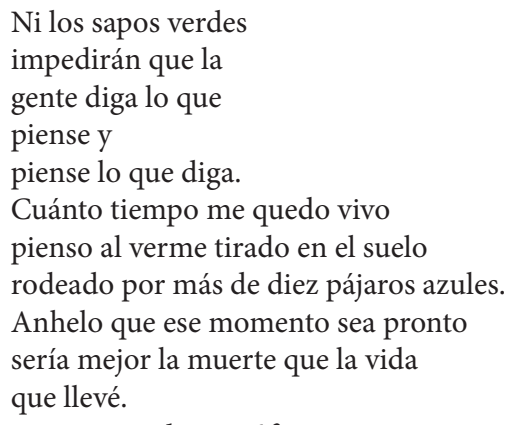

Ni los sapos verdes impedirán que la gente diga lo que piense y piense lo que diga. Cuánto tiempo me quedo vivo pienso al verme tirado en el suelo rodeado por más de diez pájaros azules.

Anhelo que ese momento sea pronto sería mejor la muerte que la vida que llevé.

En estos casos la metáfora que retuvieron los estudiantes fue tomada de «Indicios pánicos» (1970) donde mediante pájaros azules se representa a los policías que vigilan a la población.
Y mis besos ya no rozaban eso rojo que tanto me gustaba de ti Ahora cada día estabas más lejos y migrabas como un ave tomando vuelo pero aún te espero como un perro cuando espera a su dueño 
y te extraño así

como también extraño

el calor, el calor

que me transmitía tu cuerpo.

En este caso se aúnan el erotismo y la frustración de un amor interrumpido ya sea por el exilio como por prejuicios.

A modo de conclusión, señalan Artasánchez y Andriulis, recogemos sobre todo una pregunta que tiene que ver con el supuesto que luego no condice con la experiencia: por qué suponer que textos con una gran carga metafórica serán incomprendidos y rechazados por los adolescentes, cuando en un taller de aproximadamente ochenta minutos los estudiantes se entusiasman, se muestran ávidos por compartir sus distintas interpretaciones e incluso producen textos con una clara elaboración verbal y simbólica.

\section{Tercera actividad: la publicación}

En tercera instancia se publicaron todas las ponencias del encuentro en el libro 56 años Viviendo con Cristina Peri Rossi, con edición de Claudia Pérez y Néstor Sanguinetti, Montevideo, en noviembre de 2019. Un libro de 279 páginas que se distribuyó gratuitamente y que contó con un tiraje de 950 ejemplares, ochocientos de los cuales fueron distribuidos en bibliotecas y entre profesores de Literatura de Secundaria de todo el país.

El libro recogió todas las ponencias que participaron, con corrección de sus autoras y autores. Asimismo, participó en la edición un equipo de correctores coordinado por Néstor Sanguinetti. Todas las actividades se realizaron en conjunto con APLU.

Se cumplieron los objetivos planteados, ya que esta publicación adquiere un valor de consulta y referencia muy relevante sobre la obra de la autora, sirviendo como modelo para otras actividades del mismo tipo. Asimismo, se llegó a una diversidad de receptores, estudiantes, docentes, UNI 3, poetas, creadores en general.

Vale la pena destacar, en este diálogo, la siguiente exposición de Néstor Sanguinetti, que dio cuenta de un aspecto poco trabajado de la obra de Cristina peri Rossi.

\section{Palabras migrantes: desplazamientos en la obra periodística de Cristina Peri Rossi}

«Desde siempre, los escritores han pagado con el exilio, la cárcel o la muerte el poder de descubrir aquello que el poder - sea de la clase que sea-quiere mantener oculto» afirma Cristina Peri Rossi (2003, p. 262) en un artículo publicado en El Periódico de Barcelona en marzo de 1989, y su experiencia personal se ofrece como testimonio de la afirmación. 
En octubre de 1972 la escritora uruguaya debió exiliarse en Barcelona, desde donde continuó con su carrera literaria y una de sus pasiones menos frecuentadas por la crítica: el periodismo. A pesar de su extensa obra periodística — desde su temprana participación en Montevideo en El Popular y Marcha, pasando por los medios españoles El País, Diario 16, La Vanguardia, hasta su actual colaboración en la edición de El Mundo para Catalunya - es la faceta menos estudiada dentro de su producción.

El pulso del mundo. Artículos periodísticos 1978-2002, con edición e introducción de Mercedes Rowinsky (Peri Rossi, 2003), es hasta ahora la única recopilación que se dedica a esta faceta de su producción. En el prólogo se incluyen algunas anécdotas familiares referidas al periodismo: ningún diario decía la verdad afirmaba su abuela, «escéptica en materia informativa» (p. 7), o se exponen los prejuicios que tenía la propia escritora con respecto a la tarea del periodista: «el periodismo me parecía un género menor, frente a la poesía, la novela o el relato» (p. 8). A pesar del poco prestigio que, en ese entonces, adjudicaba a este género, fue la puerta de acceso al público español. Dos años después de instalarse en Barcelona, en 1974 se incorporó al plantel estable de Triunfo, medio de prensa que se transformó en el sustituto del montevideano y prestigioso semanario Marcha.

En un medio desconocido como era el español, el periodismo fue el lugar estratégico para adquirir visibilidad, el escaparate desde el cual la escritora mostraba su agudeza crítica y su fino sentido del humor, para muchos lectores fue la puerta de entrada a su literatura, que luego la conocerían mejor en sus poemas y narraciones. Triunfo se editaba en Madrid y era considerada uno de los medios que mejor representaba la resistencia antifranquista, «era una publicación de vanguardia cultural y crítica, una de las pocas que permitían cierto respiro al lector español de aquella época», dice Rowinsky (2003, p. 19). La calidad de los textos nunca le fue ajena a la escritora: «Solo tuve un lema, durante estos treinta años de periodismo: no escribir nunca una sola línea que no pueda figurar en una utópica publicación de mis Obras completas» (Peri Rossi, 2003, p. 9).

Las dos primeras secciones de El pulso del mundo... están referidas explícitamente a desplazamientos: «Viajes por el mundo» $\mathrm{y}$ «Encuentros y desencuentros del desexilio», en segunda medida, «El sueño de las ciudades» también podría incluirse en esta categoría de migraciones físicas, donde Peri Rossi (2003) recuerda: «Se viaja para contar. Cada viajero se convierte en un narrador» (p. 32) o se habla del carácter transitorio de los hoteles y del ser humano: «Los hoteles me hacen recordar que estoy en tránsito por la vida: no soy, sino estoy» (p. 53). Pero en el volumen es posible advertir otros desplazamientos, no tan literales, sino más bien simbólicos, ciertos movimientos que hablan de un salir(se) hacia otros horizontes, cuestionamientos a determinadas posiciones (quietudes, estatismos) sociales. Subversiva, cuestionado$\mathrm{ra}$, indagadora, Peri Rossi (2003) mueve (y conmueve) a sus lectores, en secciones como «Condición de mujer» o «Una cuestión de sexos», donde puede leerse: «Hay que realizar una campaña contra la violación. Y empieza por definir como violación 
toda actividad sexual arrancada a la fuerza, sea cual sea la zona erógena elegida por el macho» (p. 67); o «Es posible que dentro de 500 años la Iglesia Católica considere que el celibato era una imposición absurda y exagerada» (p. 252).

Peri Rossi concibe al artículo periodístico como un género en sí mismo, una forma particular del texto literario, entendido en el sentido de texto de creación. En ese sentido, se entiende por artículo periodístico a «todo escrito publicado por la prensa que no pertenezca al género informativo - noticia - o al género interpretativo reportaje y crónica-. Por tanto, el artículo es la forma característica del periodismo de opinión y es, en todos los casos, un discurso expresivo» (Gómez de Tejada, 2017, p. 283); al respecto opina la escritora: «la figura del intelectual que opina, que se compromete con los diversos aspectos de la realidad: se llama periodismo de firma y es al que me dedico» (Peri Rossi, 2003, p. 10).

Desde esta diversidad de temas, Peri Rossi (2003) da muestras de su compromiso ideológico, político y social en su tarea periodística: «El periodismo ha mantenido vivo mi interés por el mundo, sin el cual es imposible ejercerlo» (p. 10). Con un análisis perspicaz y atento del mundo ofrece al lector una mirada original sobre la vida cotidiana, sobre temas trascendentes o inmediatos. Se puede afirmar, entonces, que el suyo es un periodismo comprometido, que estamos ante una intelectual comprometida. Según dice Michel Foucault en «Los intelectuales y el poder», el trabajo del intelectual comprometido es decir lo verdadero a quienes aún no lo ven y en nombre de quienes no pueden decirlo: conciencia y elocuencia (Foucault, 1992, p. 80). Lejos de modelar la voluntad política de los otros, la función del intelectual es plantear interrogantes que dejen en evidencia los fundamentos de los discursos que hemos creído como verdades atemporales - por tanto, invisibles-, que configuran nuestra forma de juzgar y experimentar el mundo en el que vivimos.

\section{Conclusiones de las actividades}

Si bien el proyecto estaba destinado a privilegiar la Extensión, también se cumplió con los otros pilares de la labor universitaria. Destacamos:

- el diálogo intergeneracional e interinstitucional. Se puso en contacto voces de distintos ámbitos de formación, investigación, y de generaciones, negociando saberes y abriendo perspectivas;

- la capacidad de organizar y gestionar acciones comunitarias que los participantes del proyecto resolvieron;

- la valoración de la producción y difusión abierta de contenidos nuevos;

- valorar la positividad de estos apoyos para llevar a cabo acciones, y los esfuerzos físicos y emocionales que estas actividades generan, así como la estructura organizacional. 
Con respecto a la difusión de las actividades, se llevaron a cabo las siguientes acciones en la prensa:

\section{Antes del encuentro}

- entrevista en Tramoya, ${ }^{2}$ Radio a Pedal, a Claudia Etchechury, Andrea Arismendi y Vanesa Artasánchez;

- entrevista en La máquina de pensar, ${ }^{3}$ participantes Néstor Sanguinetti, Emanuel Andriulis y Vanesa Artasánchez.

\section{Después del encuentro}

- entrevista en La máquina de pensar a Claudia Pérez; ${ }^{4}$

- entrevista en La máquina de pensar a Andrea Arismendi;

- entrevista en La máquina de pensar a Hebert Benítez;

- entrevista en La máquina de pensar a Kildina Veljacic;

- $\quad$ artículo de Alicia Torres en Brecha; 5

- entrevista en El ático, ${ }^{6}$ Crazy FM, a Andrea Arismendi, Claudia Etchechury, Romina Serrano y Vanesa Artasánchez.

\section{Referencias}

Barthes, R. (2010). Textes choisis et présentés par Claude Coste. París: Seuil.

Foucault, M. (1992). Microfísica del poder. Madrid: Ediciones de la Piquea.

Gómez de Tejada, J. (Coord) (2017). Erotismo, transgresión y exilio: las voces de Cristina Peri Rossi. Sevilla: Editorial Universidad de Sevilla.

Peri Rossi, C. (2003). El pulso del mundo. Artículos periodísticos 1978-2002. Montevideo: Ediciones Trilce.

Rowinsky, M. (2003). Introducción. En C. Peri Rossi, El pulso del mundo. Artículos periodísticos 1978-2002. Montevideo: Ediciones Trilce.

2 https://drive.google.com/file/d/1YRm8KoMObjEKoMj_XRJyY_WNXFzidEBU/ view?fbclid=IwARoMT7UOınO_u_xcnv2mNqGHp4wI7GUdOxny9G-LBaRS94kvRomeUIR9OzI

3 http://piensamaquina.blogspot.com/search/label/Artas\% $\mathrm{C}_{3} \%$ Ainchez\%2oVanessa

4 http://piensamaquina.blogspot.com/search/label/P\%C3\%Agrez\%2oClaudia

5 https://brecha.com.uy/tan-lejos-y-tan-cerca-2/

6 https://mx.ivoox.com/es/169-el-atico-14-o9-2019-56-anos-viviendo-con-audios-mp3_rf_41410263_1.html 


\section{Programa}

PALIMPSESTO. Escrito debajo de una mujer.

9.15 Palabras de inicio a cargo de la presidenta de APLU, Prof. Mag. Silvia Viroga, la directora del Departamento de Cultura de la Intendencia de Montevideo, Mag. Mariana Percovich, y la coordinadora del Encuentro, Dra. Claudia Pérez (FHCE, Udelar).

Audio de Cristina Peri Rossi.

\subsection{0-10.45 Mesa 1: La polisemia del compromiso}

- Gabriela Sosa (CFE): Cristina Peri Rossi y las atopías del compromiso.

- Ana Belén Medori (IPA): «Los extraños objetos voladores»: una axiomática de la desaparición.

- Lucía Delbene (CES, FHCE): La poética crítica en la obra de Cristina Peri Rossi.

Modera: Néstor Sanguinetti.

\subsection{5-12.00 Mesa 2: Palimpsestos}

- Vanesa Artasánchez y Claudia Etchechury (FHCE): Transtextualidades en El libro de mis primos.

- Claudia Panisello (CES): La nueva modelización del mundo en El libro de mis primos de Cristina Peri Rossi.

- Gabriela Andrea Marrón (UNS, CONICET): "Quédese con el ancla». Notas de lectura a Todo lo que no te pude decir.

- Claudia Përez (FHCE): Navigare necesse est, vivere non necesse. Una lectura del desplazamiento signico en La nave de los locos.

Modera: Vanesa Artasănchez.

\subsection{0-12.15 Pausa café}

\subsection{5-13.00 Mesa 3: Lecturas / Performáticas}

Valentina Dos Santos, Ailín Curbelo, Teresa Samurio, Magdalena Portillo, Virginia Finozzi y Romina Serrano.

Modera: Romina Serrano.

\subsection{0-14.15 Mesa 4: Variaciones sobre el ser deseante}

- Andrea Arismendi (CES, FHCE): Cuerpos subversivos, cuerpos disidentes.

- Valentina Dos Santos (FHCE): La Naturaleza, régimen establecido.

- Gloria Salbarrey (IPA): Juego, deseo e inteligencia en Cristina Peri Rossi.

Modera: Emanuel Andriulis. 


\subsection{5-15.30 Mesa 5: Construcción de lo femenino, construcción de lo diverso}

- Pilar de León (FHCE, CFE): Un diálogo desarticulado y fragmentario con los principios fundamentales de la creación: el goce, el dolor, la pasión, el deseo.

- Emanuel Andriulis (FHCE): La novísima literatura: el estado de exilio como poética en Peri Rossi.

- Valentina Tabeira (FHCE): La noción de equivocado en "De noche, la lluvia", "Ne me quitte pas» y «Todo iba bien» de Cristina Peri Rossi.

- Kildina Veljacic (FHCE, CES): Representaciones de la feminidad en Los museos abandonados y en El museo de los esfuerzos inútiles de Cristina Peri Rossi.

Modera: Pilar de León.

\subsection{0-15.45 Pausa café}

\subsection{5-17.00 Mesa 6: Interdiscursividades disciplinarias. Filosofía y psicoanálisis}

- Mariana Aja (CES): Devolver el asombro al mundo: sujetos del rendimiento y entretiempos en Habitaciones privadas de $\mathrm{C}$. Peri Rossi.

- Lucía Redes y Romina Serrano (FHCE): Para seguir viviendo es necesario olvidar que se vivió. Una lectura de Los amores equivocados de Cristina Peri Rossi.

- Soledad Silva (APU): Literatura y psicoanálisis.

- Emiliano Pereira y Helena Modzelewski (FHCE): "Los desarraigados» y la educación pluralista.

Modera: Teresa Samurio.

\subsection{0-18.15 Mesa 7: Compromiso de escritura}

- María del Carmen González (CFE): Eros, logos y distancia en la escritura de Cristina Peri Rossi.

- Néstor Sanguinetti (CFE, UCU): Periodismo y compromiso.

- Margarita Muñiz (CES, APU): Querida Cris: acercamiento a través de diálogos virtuales.

- Hebert Benitez (FHCE, CFE): Evoné, cuerpo y poesia: Ias implosiones del deseo.

Modera: Lucía Redes.

\subsection{5-18.30 Pausa café}

\subsection{0-19.45 Mesa 8: Escritoras en diálogo}

Laura Fumagalli, Claudia Panisello, Lourdes Peruchena, Sylvia Riestra.

Modera: Claudia Pérez.

Palabras finales. Brindis. 